\title{
15. STATISTICAL ANALYSIS OF GEOCHEMICAL LOGGING TOOL DATA FROM HOLE 735B, ATLANTIS FRACTURE ZONE, SOUTHWEST INDIAN OCEAN1
}

\author{
R. Pelling, ${ }^{2}$ P. K. Harvey, ${ }^{3}$ M. A. Lovell,${ }^{3}$ and D. Goldberg ${ }^{4}$
}

\begin{abstract}
Data derived from the geochemical logging tool (GLT) used to log the basement gabbros of Hole 735B in the Atlantis II Fracture Zone show a wide variation in geochemical composition. Statistical analysis of these data, primarily principal component analysis and iterative nonhierarchical cluster analysis (INCA), has been employed to classify these data into geochemically similar groups to produce a statistically derived chemostratigraphy for the borehole. The derived chemostratigraphy is in excellent agreement with the lithostratigraphy defined from study of core specimens conducted by the Shipboard Scientific Party (SSP, 1989), but in addition highlights some apparently geochemically anomalous regions in the borehole, which should be the focus for further examination.
\end{abstract}

\section{INTRODUCTION}

Schlumberger's new geochemical logging tool (GLT) string has great potential as an aid for determining geology downhole. The results from this state-of-the-art tool can be processed to estimate the relative elemental abundances of most of the major elements found in the rocks.

With further processing of the these elemental data using a suitable oxide closure model (Hertzog et al., 1989), an estimate was obtained of the major oxide chemistry of the rocks over the entire logged interval, which represents a considerable improvement over having these data at only a few points where core has been analyzed. Having a continuous estimate of the major oxide chemistry broadens the horizons of wireline logging in studies of the oceanic crust and offers the prospect of classification of the igneous rocks encountered downhole on the basis of chemical composition or pseudomineralogy.

The accuracy of the geochemistry determined by the GLT remains open to question, and development will need to continue for some time. However, even if the results may not be directly comparable with laboratory-derived X-ray fluorescence spectroscopy (XRF) results, one may reasonably assume that they are internally consistent and that their variation represents changes in the chemical, or indirectly, physical properties of the formations through which the tool string has passed.

The Schlumberger GLT is made up of four separate wireline tools. The uppermost component of the GLT string is an auxiliary measurement sonde (AMS) that measures mud resistivity and temperature to allow borehole salinity and, ultimately, a borehole neutron absorption cross section to be calculated. This is required during initial processing of the neutron logging data. Below the AMS is a telemetry cartridge that relays the logging measurements up the cable to recording equipment aboard the ship.

\footnotetext{
${ }^{1}$ Von Herzen, R. P., Robinson, P. T., et al., 1991. Proc. ODP, Sci. Results, 118: College Station, TX (Ocean Drilling Program).

2 Department of Geology, University of Nottingham, Nottingham, NG7 2RD, U.K. U.K.

Department of Geology, University of Leicester, Leicester, LE1 7RH,

${ }_{4}^{4}$ Lamont-Doherty Geological Observatory, Columbia University, Palisades, NY, U.S.A.
}

A standard natural gamma spectroscopy tool (NGT) comes next, and this determines the abundances of the naturally radioactive elements in the formation, namely potassium, uranium, and thorium. This is a standard NGT, as used routinely in hydrocarbon exploration.

The next two components of the string form a source and detector combination that determines the amount of aluminum in the formation. The source component is a modified compensated neutron porosity tool (CNT-G) in which the usual americium-beryllium source has been replaced by a californium-252 source that emits a lower-energy neutron flux more suitable for activating aluminum atoms. Neutrons from the source are absorbed by aluminum atoms in the formation, creating instability, which results in the emission of gamma rays of characteristic energies that are detected and recorded by the aluminum activation clay tool (AACT). The AACT is a modified version of the NGT that has three extra detection windows on the spectrometer; these serve to optimize it for detecting the gamma-ray spectrum emitted by the activated aluminum atoms.

A gamma spectroscopy tool (GST) completes the tool string. This uses a $14-\mathrm{MeV}$ minitron neutron generator to bombard the formation with neutrons and thus induce capture reactions. When an atom captures a neutron, it becomes unstable and emits a characteristic spectrum of gamma rays. The GST records this spectrum, which in turn can be resolved to give estimates of the relative abundances of a number of elements. Whether an element can be detected in this way depends on its neutron capture cross section, its absolute abundance, and the possible effects of other elements that might cause spectral interference. These parameters are favorable for detecting calcium, silicon, iron, sulfur, titanium, gadolinium, hydrogen, and chlorine. Normally, a boron sleeve would encase the GST and reduce unwanted signals from hydrogen (which, along with chlorine, is mainly present in fluids). The diameter of ODP boreholes is insufficient to allow the boron sleeve to be used. A more detailed description of the GLT tool is given by Hertzog et al. (1989).

The GLT is potentially capable of determining the abundance of silicon, titanium, aluminum, iron, calcium, potassium, uranium, thorium, gadolinium, sulfur, hydrogen, and chlorine. Using these data, together with the photoelectric factor (PEF) obtained from a lithodensity tool (LDT), a tentative estimate for magnesium may also be made (Hertzog et al., 1989). The total PEF of a formation is the sum of the 
PEF contributions of all elements in the formation. The difference between a theoretically calculated PEF using the elements measured by the GLT, and the LDT-derived PEF measurement is assumed to be primarily the result of the contribution of magnesium and sodium, which are the only undetermined major elements. In gabbros, such as those encountered in Hole 735B, magnesium is usually in excess of sodium and the PEF difference can be taken to represent an estimate for magnesium. However, in other rocks, such as metabasalts, this may not be a valid assumption. In particular, in Hole 735B, sodium in the trondhjemitic veins is greatly in excess of magnesium.

\section{The Use of GLT Results}

Geochemistry obtained by the GLT can be processed to represent almost the complete set of major oxides commonly occurring in igneous rocks. The abundance of some minor elements is also available: uranium, thorium, gadolinium, and sulfur. The hydrogen and chlorine data have not been used in this study because both are primarily found in borehole fluids. The GLT offers two main advantages over laboratory-based XRF analysis: first, it provides a continuous profile of chemical variations over the entire logged interval, and second, it produces results much quicker than XRF. The GLT can give relative elemental abundances during logging and, after a few hours processing, the dry weight percentage oxide abundances. This time scale compares favorably with the months required for selection, preparation, and laboratory analysis of core samples.

By collecting the geochemical data obtained from the GLT and then processing it by computer, it is possible to produce statistically based chemostratigraphical subdivisions throughout the borehole. Hole 735B represents an excellent testing ground for this technique because a wide variation in chemical composition exists within the rock, making it relatively easy to classify the GLT data into distinct groups. Another factor that makes Hole 735B ideal for this work is the exceptionally high core recovery $(87 \%)$, which allows for an accurate comparison of the chemostratigraphy to the lithostratigraphy produced by a study of the core by shipboard scientists.

\section{Location and Geology of Site ${ }^{5}$}

Hole 735B is located on a shallow platform on the east rim of the Atlantis II Fracture Zone in the southwest Indian Ocean; it was drilled to a depth of $500.7 \mathrm{mbsf}$ during Leg 118. During the tectonic evolution of the fracture zone, lower crustal gabbros were emplaced at a high level on this platform, and it is into these gabbros that the hole was drilled. Tectonic activity subjected the rocks to varying degrees of plastic and brittle deformation, which resulted in the destruction of the original igneous textures in some zones. On the basis of mineralogy and nature of deformation observed in core specimens, the section was subdivided into six lithostratigraphical units by shipboard scientists (Robinson, Von Herzen, et al., 1989).

Lithologic Unit I (0-37.4 mbsf) is made up of foliated metagabbro that exhibits porphyroclastic to mylonitic textures that completely obscure the original igneous textures. Also present in Unit I are a few secondary Fe-Ti oxide layers, which occur as fracture infill. The occurrence of clearly igneous textures at 37.4 mbsf has been chosen to mark the top of Unit II (37.4-170.2 mbsf), which is a 132.8-m-thick sequence of olivine gabbro and olivine-bearing gabbro. Most of

\footnotetext{
${ }^{5}$ After this paper was accepted for publication, new lithostratigraphy was produced (Dick et al., this volume). These new data were unavailable for modifying some of the figures, text, tables, which were created on the basis of old shipboard data (February 6, 1991).
}

the gabbros in the unit are mesocumulates, in which primary layering is defined by grain-size variations. The rocks are fairly primitive, with $\mathrm{MgO}$ contents of 9 to $12 \mathrm{wt} \%$ and scattered layers of Fe-Ti oxide-bearing gabbro.

Unit III (170.2-223.6 mbsf) is macroscopically similar to Unit II, but contains rocks that are more evolved (8-9 wt\% $\mathrm{MgO}$ ). The change is gradational, and the boundary defined by the occurrence of sodic plagioclase, low calcium pyroxene, and iron-rich olivine. Within the unit, mylonitic and foliated zones are common and a 0.6 -m-thick mylonite occurs at its base. The change into Unit IV is gradational.

Unit IV (223.6-274.1 mbsf) is a 50.5-m-thick sequence of $\mathrm{Fe}-\mathrm{Ti}$ oxide-rich gabbro that contains exceptionally high amounts of $\mathrm{FeO}^{*}$ (up to $27 \mathrm{wt} \%$ ) and $\mathrm{TiO}_{2}$ (up to $9 \mathrm{wt} \%$ ). At two levels within this unit, a felsic intrusion breccia was identified that contains trondhjemite veins. A 3-m-thick mylonite zone marks the base of the unit and the top of Unit V (274.1-382.4 mbsf). The latter comprises $108.3 \mathrm{~m}$ of relatively uniform olivine gabbros characterized by a scarcity of $\mathrm{Fe}-\mathrm{Ti}$ oxides. The gabbros of Unit V are mineralogically and chemically similar to those of Unit II and, as in Unit II, most are mesocumulates, with layering defined by primary grain-size variations. Brecciated zones featuring felsic veins are common within Unit V.

The bottom $118.3 \mathrm{~m}$ of the hole is olivine-rich gabbro having numerous layers of troctolite, which constitutes Unit VI (382.4-500.7 mbsf). In many ways, these gabbros are similar to those found in Unit V; however, higher modal olivine was found in Unit VI. Grain-size-defined layering is common, and lenses and layers of microgabbro exist within the unit. Troctolites and troctolitic gabbros are interlayerd with the olivine gabbros, and these have been interpreted as small intrusive layers. With up to $25 \mathrm{wt} \% \mathrm{MgO}$, these troctolites represent the most mafic material encountered in Hole $735 \mathrm{~B}$. Numerous intervals of metagabbro also occur in Unit VI.

\section{STATISTICAL INVESTIGATIONS}

\section{Introduction}

Measurements were performed using the GLT at intervals of $0.152 \mathrm{~m}$ throughout the borehole; this provided a large data set. Because of the difficulties of characterizing and representing data of this type, a multivariate statistical approach was adopted. Initially, principal component analysis was used to evaluate overall variability and to reduce dimensionality for subsequent processing. Finally, an iterative nonhierachical cluster analysis (INCA) was employed to classify the log responses and to generate a chemostratigraphy.

Summary statistics for the GLT data obtained from the borehole are presented in Table 1. The mean values are of the right order for gabbroic rocks. Note the exceptionally high maximum values obtained for $\mathrm{FeO}^{*}(32.7 \%)$ and $\mathrm{TiO}_{2}(8.93 \%)$, which are associated with $\mathrm{Fe}-\mathrm{Ti}$ oxide-rich zones, where $\mathrm{SiO}_{2}$ occurs at abnormally low concentrations (minimum $12.44 \%$ ). $\mathrm{SiO}_{2}$ also has an unexpectedly high maximum value $(64.21 \%)$, possibly reflecting felsic intrusion breccia layers, described by the SSP in Units IV and V. As discussed above, the measurements are not entirely accurate, and the spectral stripping involved may have introduced errors, resulting in negative values. In these data, the minimum value obtained for $\mathrm{TiO}_{2}$ is $-0.574 \%$. This phenomenon also was encountered in a study of the GLT responses in Hole 504B (Brewer et al., 1990), where problems of measurement and sampling using the GLT have been discussed in more detail. Negative $\mathrm{TiO}_{2}$ values were not removed from the data set because they probably reflect real whole-rock geochemical changes and may be useful in subdivision of the rocks encountered downhole by the GLT. 
Table 1. Summary of statistics from Hole 735B GLT data.

\begin{tabular}{lrccc}
\hline & Mean & Std. dev. & Minimum & Maximum \\
\hline $\mathrm{SiO}_{2}$ & 47.255 & 6.135 & 12.44 & 64.21 \\
$\mathrm{Al}_{2} \mathrm{O}_{3}$ & 15.026 & 2.204 & 8.30 & 22.98 \\
$\mathrm{TiO}_{2}$ & 1.068 & 1.479 & $(0.00)$ & 8.93 \\
$\mathrm{FeO}^{*}$ & 10.714 & 4.209 & 5.96 & 32.70 \\
$\mathrm{MgO}^{\prime}$ & 9.867 & 1.989 & 2.31 & 16.76 \\
$\mathrm{CaO}$ & 15.761 & 3.139 & 2.22 & 29.42 \\
$\mathrm{~K}_{2} \mathrm{O}$ & 0.124 & 0.041 & 0.04 & 0.35 \\
$\mathrm{~S}$ & 0.189 & 0.556 & 0.00 & 5.83 \\
$\mathrm{U}$ & 0.180 & 0.097 & 0.015 & 1.16 \\
$\mathrm{Th}$ & 0.287 & 0.303 & 0.000 & 4.08 \\
$\mathrm{Gd}$ & 4.805 & 2.481 & 1.657 & 27.72 \\
\hline
\end{tabular}

Note: All oxide and sulfur data are in weight percent; values of $\mathrm{Th}, \mathrm{U}$, and $\mathrm{Gd}$ are in parts per million. $\mathrm{FeO}^{*}$ is total iron expressed as $\mathrm{FeO} . \mathrm{MgO}^{\prime}$ is the derived $\mathrm{MgO}$ value, which includes a sodium contribution. The parentheses around the minimum value for $\mathrm{TiO}_{2}$ indicate that subzero responses exist, down to -0.574 (see text for explanation).

General relationships within the data are summarized in Table 2, which gives the linear correlation matrix. Most correlations, while statistically significant, are relatively weak, an expression of the mixed range of gabbros present. The matrix is summarized in Figure 1, which depicts the strong correlation between iron and titanium, the oxide components, and sulfur, representing the sulfides (pyrite) present. Weaker, but significant, positive correlations of $\mathrm{SiO}_{2}$ with $\mathrm{Al}_{2} \mathrm{O}_{3}$ overall (Fig. 1), negatively related to the other elements, are an expression of the silicate vs. oxide association that dominates the mineralogy, together with the closed oxide effects predictable for $\mathrm{SiO}_{2}$.

\section{Principal Component Analysis}

Principal component analysis was conducted on all the GLT elements, using the correlation matrix (Table 2). This is equivalent to performing the analysis on standardized variables, with zero mean and unit standard deviation, so that all elements are considered equally, regardless of their absolute concentrations. Table 3 presents the eigenvalues and percentage contributions for each of the 11 eigenvectors. The loadings

Table 2. Linear $(r)$ correlation matrix for Hole 735B GLT data.

\begin{tabular}{|c|c|c|c|c|c|c|}
\hline & $\mathrm{SiO}_{2}$ & $\mathrm{Al}_{2} \mathrm{O}_{3}$ & $\mathrm{TiO}_{2}$ & $\mathrm{FeO}^{*}$ & $\mathrm{MgO}^{\prime}$ & $\mathrm{CaO}$ \\
\hline $\mathrm{SiO}_{2}$ & 1.000 & $0.167^{*}$ & $-0.601^{*}$ & $-0.677^{*}$ & $-0.604^{*}$ & $-0.443^{*}$ \\
\hline $\mathrm{Al}_{2} \mathrm{O}_{3}$ & - & 1.000 & $-0.541^{*}$ & $-0.565^{*}$ & $-0.200^{*}$ & $0.138^{*}$ \\
\hline $\mathrm{TiO}_{2}$ & - & - & 1.000 & $0.928^{*}$ & $0.107^{*}$ & $-0.282^{*}$ \\
\hline $\mathrm{FeO}^{*}$ & - & - & - & 1.000 & $0.191^{*}$ & $-0.231^{*}$ \\
\hline $\mathrm{MgO}^{\prime}$ & - & - & - & - & 1.000 & $0.360^{*}$ \\
\hline \multirow[t]{2}{*}{$\mathrm{CaO}$} & - & - & - & - & - & 1.000 \\
\hline & $\mathrm{K}_{2} \mathrm{O}$ & $\mathbf{S}$ & $\mathrm{U}$ & $\mathrm{Th}$ & Gd & \\
\hline $\mathrm{SiO}_{2}$ & $-0.046=$ & $-0.303^{*}$ & $0.052^{*}$ & $0.127^{*}$ & $-0.377^{*}$ & \\
\hline $\mathrm{Al}_{2} \mathrm{O}_{3}$ & $-0.057^{*}$ & $-0.150^{*}$ & $-0.122^{*}$ & $-0.062^{*}$ & $-0.301^{*}$ & \\
\hline $\mathrm{TiO}_{2}$ & $0.155^{*}$ & $0.285^{*}$ & 0.006 & $-0.110^{*}$ & $0.447^{*}$ & \\
\hline $\mathrm{FeO}^{*}$ & $0.180^{*}$ & $0.283^{*}$ & $0.063^{*}$ & $-0.072^{*}$ & $0.562^{*}$ & \\
\hline $\mathrm{MgO}^{\prime}$ & $-0.149^{*}$ & $0.131^{*}$ & -0.036 & -0.032 & $0.093^{*}$ & \\
\hline $\mathrm{CaO}$ & $-0.120^{*}$ & $-0.078^{*}$ & $-0.099^{*}$ & -0.034 & $-0.117^{*}$ & \\
\hline $\mathrm{K}_{2} \mathrm{O}$ & 1.000 & $0.098^{*}$ & $0.253^{*}$ & 0.001 & $0.341^{*}$ & \\
\hline $\mathrm{S}$ & - & 1.000 & $0.088^{*}$ & -0.009 & $0.205^{*}$ & \\
\hline $\mathrm{U}$ & - & - & 1.000 & $0.492^{*}$ & $0.305^{*}$ & \\
\hline Th & - & - & - & 1.000 & $0.126^{*}$ & \\
\hline Gd & - & - & - & - & 1.000 & \\
\hline
\end{tabular}

Note: $r$ is significantly different from zero at alpha $=0.05$ followed by $=\cdot r$ is significantly different from zero at alpha $=0.01$ followed by ${ }^{*}$. Number of cases $=2995$. $\mathrm{FeO}^{*}$ is total iron expressed as $\mathrm{FeO} \mathrm{MgO}^{\prime}$ is the derived $\mathrm{MgO}$ value, which includes a sodium contribution. for the first four components, those with eigenvalues greater than 1.0, are given in Table 4. The first four components account for just over $70 \%$ of the total variation. Virtually all variation $(>89 \%)$ in $\mathrm{SiO}_{2}, \mathrm{FeO}^{*}$, and $\mathrm{TiO}_{2}$ is included within these components. $\mathrm{Al}_{2} \mathrm{O}_{3}, \mathrm{MgO}^{\prime}$, sulfur, and gadolinium are the least-constrained elements, with less than $70 \%$ of their variation being accounted for in the first four components.

The first component is strongly correlated with $\mathrm{SiO}_{2}$ and $\mathrm{Al}_{2} \mathrm{O}_{3}$, together with strong negative correlations with $\mathrm{FeO}^{*}$ and $\mathrm{TiO}_{2}$. This can be interpreted as being a result of overall variation of rock composition, particularly emphasizing the difference between normal gabbros and the Fe-Ti oxide-rich varieties.

The second component is dominated by $\mathrm{CaO}$ and $\mathrm{MgO}^{\prime}$ and has been tentatively interpreted as reflecting variation in the mineralogical composition of the gabbros. The strong correlation of $\mathrm{CaO}$, and to a much weaker extent, $\mathrm{Al}_{2} \mathrm{O}_{3}$, with this component, together with the inverse behavior of $\mathrm{SiO}_{2}$ and $\mathrm{K}_{2} \mathrm{O}$, is suggestive of variation in feldspar composition. The high positive correlation of $\mathrm{MgO}^{\prime}$ may then be interpreted in terms of an association between more calcic feldspars and more magnesian mafic phases. Complications arise with this interpretation because of the low loading for $\mathrm{Al}_{2} \mathrm{O}_{3}$ and the fact that, for at least some log responses, there is a strong sodium contribution in the $\mathrm{MgO}^{\prime}$ values. An alternative interpretation is that this is an alteration component, a suggestion backed up by the negative loadings for $\mathrm{SiO}_{2}, \mathrm{~K}_{2} \mathrm{O}$, and uranium.

The third component is dominated by two of the naturally occurring radioactive elements, thorium and uranium, together with $\mathrm{CaO}$. In view of the low abundance of these elements in basic rocks, their occurrence together in significant concentrations suggests mobilization, with this component possibly associating with deformed zones in the sequence.

Principal component four has a strong correlation with $\mathrm{K}_{2} \mathrm{O}$, and to a lesser extent $\mathrm{Al}_{2} \mathrm{O}_{3}$, and probably represents felsic/trondhjemitic material, which was noted at a few places in the borehole. Although trondhjemites are characteristically low in $\mathrm{K}_{2} \mathrm{O}$, the maximum value recorded from the log data is only $0.35 \%$ (Table 1 ), while the one trondhjemite analysis recorded in the Initial Reports volume for Leg 118 (Robinson, Von Herzen, et al., 1989) gave $1.48 \%$ $\mathrm{K}_{2} \mathrm{O}$. Further, as discussed below, there is a precise correlation between log responses having high scores for component four and the occurrence of felsic/trondhjemitic veins in the core samples.

The fifth component is dominated by sulfur, accounting for $75.6 \%$ of its variation. This component has not been used in the $\log$ analysis discussed below as it provides virtually no more information than can be gained from the variation in sulfur alone. In addition, sulfur is not a major rock-forming element and occurs mainly in sulfides and secondary minerals associated with alteration by late-stage fluids derived from seawater. Removal of sulfur by this component analysis should allow the original rock chemical variations to be picked out more clearly.

Scores for the first four principal components were calculated from the component loadings and were normalized to yield standardized scores, with a zero mean and unit standard deviation. These scores were used in further processing, as described next.

\section{Iterative Nonhierarchical Cluster Analysis (INCA)}

INCA is a classification technique employed here to characterize the GLT responses and to help define any chemostratigraphic zonation that might be identified from these data. 


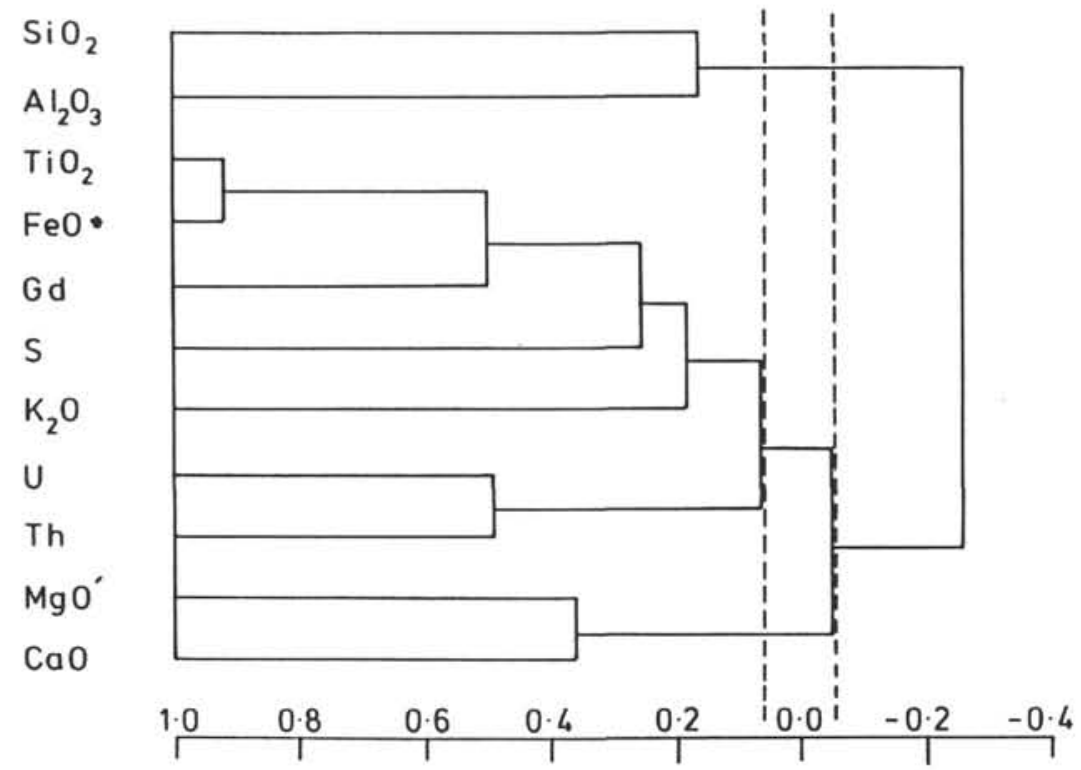

Figure 1. Dendrogram summarizing the relationships between the 11 GLT variables for the complete log. Data were clustered using the correlation matrix and a simple average method. Co-phenetic correlation is $\mathbf{0 . 8 4 5}$. Correlations between the dashed lines are insignificant at alpha $=0.05$.

Table 3. Eigenvalues and percentage contributions.

\begin{tabular}{cccc}
\hline Component & $\begin{array}{c}\text { Eigenvalues } \\
(\%)\end{array}$ & Eigenvalues & $\begin{array}{c}\text { Cumulative } \\
\text { eigenvalues (\%) }\end{array}$ \\
\hline 1 & 3.470 & 31.54 & 31.54 \\
2 & 1.978 & 17.98 & 49.53 \\
3 & 1.495 & 13.59 & 63.11 \\
4 & 1.054 & 9.58 & 72.69 \\
5 & 0.879 & 7.99 & 80.68 \\
6 & 0.643 & 5.84 & 86.53 \\
7 & 0.515 & 4.68 & 91.22 \\
8 & 0.471 & 4.29 & 95.49 \\
9 & 0.435 & 3.96 & 99.45 \\
10 & 0.061 & 0.55 & 100.00 \\
11 & 0.000 & 0.00 & 100.00 \\
\hline
\end{tabular}

Components extracted from the sample linear correlation matrix.

Table 4. Principal component loadings for the first four components.

\begin{tabular}{lrrrrr}
\hline Component & \multicolumn{1}{c}{1} & \multicolumn{1}{c}{2} & \multicolumn{1}{c}{3} & \multicolumn{1}{c}{4} & \%Acc. \\
\hline $\mathrm{SiO}_{2}$ & 0.7429 & -0.5595 & -0.2096 & -0.1547 & 93.27 \\
$\mathrm{Al}_{2} \mathrm{O}_{3}$ & 0.6154 & 0.1454 & 0.0820 & 0.4681 & 62.57 \\
$\mathrm{TiO}_{2}$ & -0.8855 & -0.0642 & -0.3067 & -0.1010 & 89.25 \\
$\mathrm{FeO}^{*}$ & -0.9408 & -0.0456 & -0.1942 & -0.0759 & 93.06 \\
$\mathrm{MgO}^{\prime}$ & -0.3581 & 0.6264 & 0.3836 & -0.1666 & 69.55 \\
$\mathrm{CaO}$ & 0.1021 & 0.6915 & 0.5051 & 0.1920 & 78.06 \\
$\mathrm{~K} 2$ & -0.2614 & -0.4251 & 0.0870 & 0.7182 & 77.25 \\
$\mathrm{~S}$ & -0.4325 & -0.0010 & 0.0426 & 0.1519 & 21.19 \\
$\mathrm{Th}$ & 0.0293 & -0.4349 & 0.6655 & -0.3714 & 77.07 \\
$\mathrm{U}$ & -0.1586 & -0.5614 & 0.6436 & -0.0295 & 75.54 \\
$\mathrm{Gd}$ & -0.6710 & -0.2865 & 0.2079 & 0.2289 & 62.80 \\
\hline
\end{tabular}

$\%$ Acc. = percent of the variation accounted for by the first four components.

Two sets of analyses are reported: one using elemental data, and the other, the component scores discussed above. A brief description of the technique is given first.

INCA is a simple method, available for a number of years under one name or another (for example: K-means clustering, relocation analysis). The method proved useful for interpret- ing GLT data from Hole 504B (Brewer et al., 1990). The object of the technique is to split (classify) a multivariate data set into groups of samples (log responses) having similar characteristics. While the basic idea is straightforward, there are an almost unlimited number of variants, and little systematic study has been done for what is undoubtedly a powerful technique.

In its simplest form, consider a two-dimensional case (Fig. 2A), where two obvious (but as yet unknown) clusters are present. Given the coordinates for all of the points, two points are chosen to act as initial seed points (A and B in Fig. $2 A)$. These may be chosen in a number of ways and need not be actual data points. The next step is to assign all other points to a group centered either at point $\mathrm{A}$ or point $\mathrm{B}$, depending on which centroid is closer (Fig. 2B). When all points have been assigned, new centroids are calculated for each cluster as the average of all samples allocated to that cluster (Fig. 2C). Using the new centroids, each sample is reassigned to its nearest centroid (Fig. 2D). In turn, a new pair of centroids are computed. The process of reassignment and computation of centroids continues until the system converges (no further relocations) or a set number of iterations has been completed. In this example, the technique is nonparametric and uses the nearest (euclidian) centroid as the basis of a classification rule. Other variations of the method allow (1) sample inter-correlations to be accommodated, (2) samples to be allocated on a probabilistic basis, or (3) sample point densities to be considered. One major problem with all variants, however, is the choice of the number of groups, which is obvious in the two-dimensional example above, but not so in a multidimensional situation. More details of the technique in a geological context are given by Shepherd et al. (1987).

In the two analyses discussed next, the euclidian model has been used for data standardized to zero mean and unit standard deviation. The number of groups was chosen by running the analyses for 2 through 15 groups and choosing the "optimum" number of groups from "within groups sums of squares" (WGSS) statistics. With increasing number of groups, the WGSS decreases and then tends to a constant 

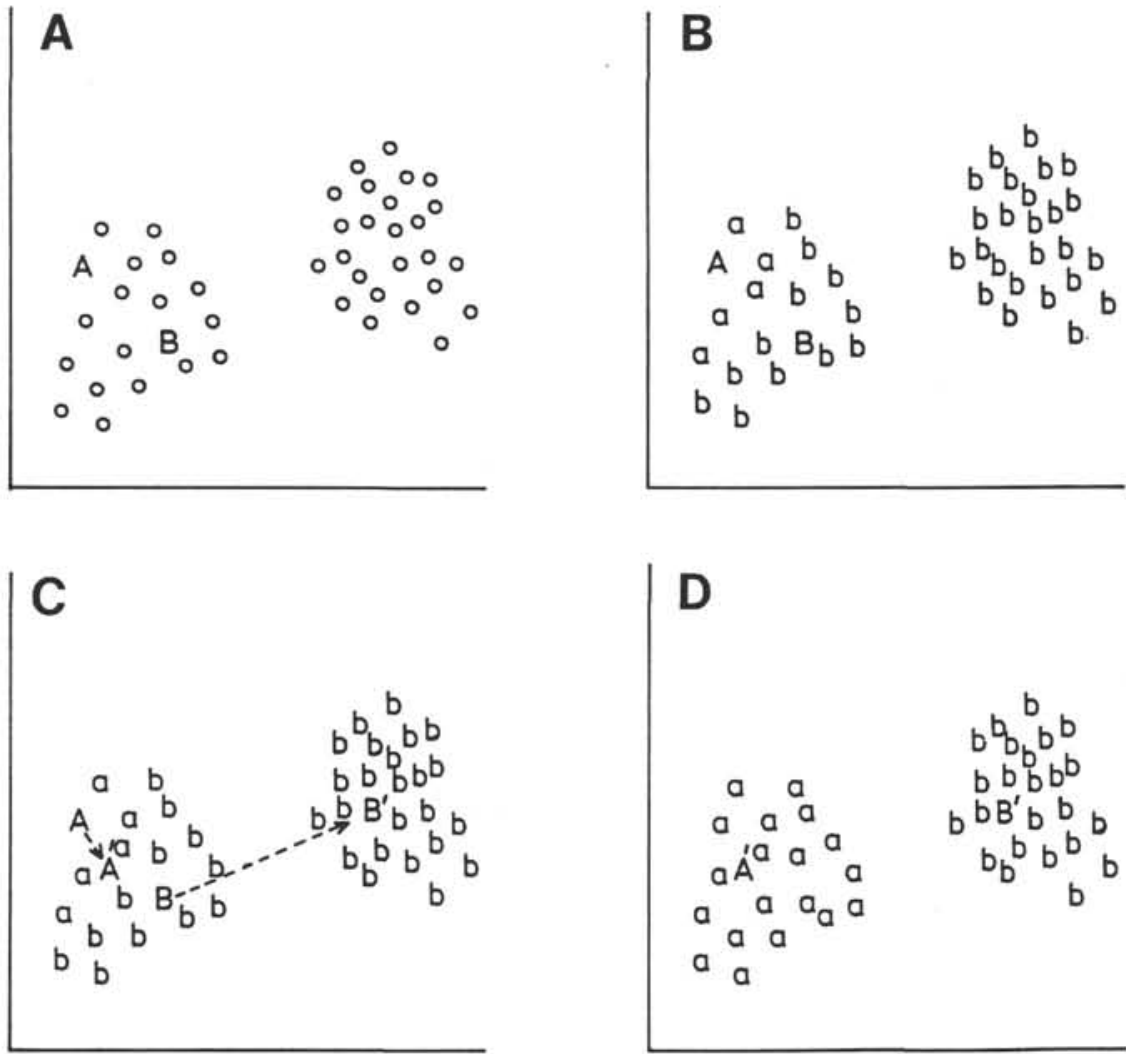

Figure 2. Principles of iterative nonhierarchical cluster analysis (see text for explanation).

Table 5. Group abundance and centroid compositions (INCA Model 1).

\begin{tabular}{|c|c|c|c|c|c|c|c|}
\hline Group & 1 & 2 & 3 & 4 & 5 & 6 & Delt: \\
\hline $\mathrm{SiO}_{2}$ & 47.595 & 52.599 & 47.274 & 38.819 & 27.212 & 42.064 & 2.59 \\
\hline $\mathrm{Al}_{2} \mathrm{O}_{3}$ & 14.485 & 15.430 & 16.183 & 12.716 & 11.638 & 11.987 & 1.35 \\
\hline $\mathrm{TiO}_{2}$ & 0.707 & 0.768 & 0.374 & 3.222 & 5.100 & 4.655 & 3.76 \\
\hline $\mathrm{FeO}^{*}$ & 10.013 & 9.642 & 8.699 & 16.632 & 23.432 & 19.955 & 3.62 \\
\hline $\mathrm{MgO}^{\prime}$ & 10.532 & 7.676 & 10.318 & 11.315 & 12.723 & 9.477 & 1.23 \\
\hline $\mathrm{CaO}$ & 16.422 & 13.606 & 16.973 & 14.522 & 19.358 & 11.660 & 1.16 \\
\hline $\mathrm{K}_{2} \mathrm{O}$ & 0.151 & 0.137 & 0.095 & 0.145 & 0.152 & 0.122 & 0.81 \\
\hline $\mathrm{S}^{2}$ & 0.100 & 0.148 & 0.091 & 2.631 & 0.387 & 0.084 & 1.91 \\
\hline $\mathrm{U}$ & 0.198 & 0.233 & 0.140 & 0.227 & 0.194 & 0.147 & 0.57 \\
\hline Th & 0.268 & 0.461 & 0.230 & 0.268 & 0.231 & 0.164 & 0.40 \\
\hline Gd & 4.979 & 5.332 & 3.597 & 5.858 & 11.550 & 5.547 & 1.28 \\
\hline $\begin{array}{l}\text { Number in } \\
\text { group }\end{array}$ & 834 & 639 & 1141 & 88 & 98 & 195 & \\
\hline
\end{tabular}

Units as in Table 1. Delta is a measure of the importance of the given variable in separating the groups.

value. If the groups are distinct, there will be a break in the WGSS figures at the "optimum" number of groups. Because of averaging during processing, the GLT data are strongly auto-correlated, and distinct groups cannot occur. In addition, geochemical data frequently represent gradational changes between end-member compositions. The number of groups chosen thus are not optimal in the true sense, but represent convenient divisions within the data whose boundaries are strictly gradational. In addition to group membership for each log response, the analysis yields the centroid compositions for each group and the positions of each group relative to each other group. Initial seed points in all cases were chosen using Ball and Hall's method (1967), where samples are selected as seeds in such a way that every seed is at least a given distance from each other seed. This procedure ensures that seed points are well distributed within the data set and considerably hastens convergence.

\section{INCA Analysis of GLT Data (Model 1)}

The first analysis was performed on the chemical data for all 11 elements, following their standardization to a zero mean and unit standard deviation. In total, there are 2995 sets of $\log$ responses through the $454 \mathrm{~m}$ of basement rock logged (13-467 mbsf). Initial testing for the number of groups resulted in six being chosen for a full analysis; 10 iterations were performed. Table 5 contains details of the centroid compositions of the six groups produced, and the number of points allocated to each group. Group centroids are expressed in the original weight percent or parts per million elemental units after recalculation from the standardized centroids derived by the analysis. 


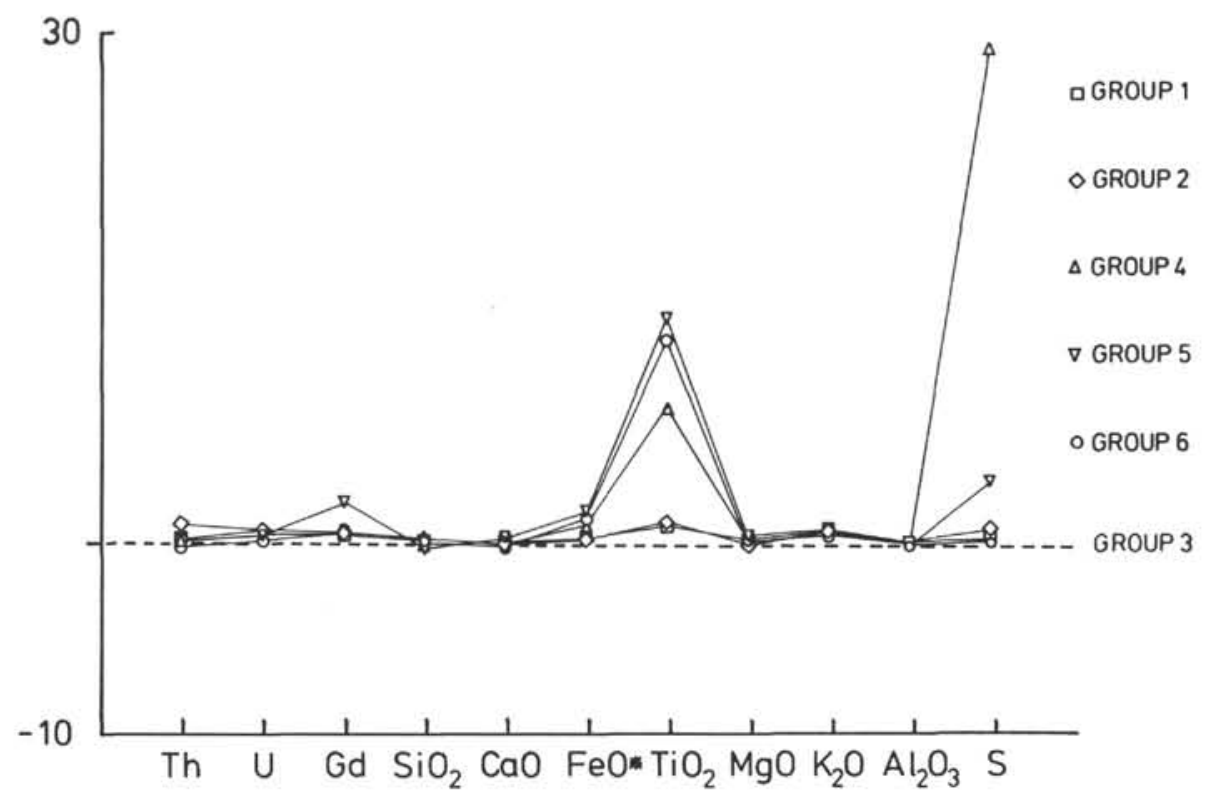

Figure 3. Spidergram of INCA (Model 1) centroids for the GLT data. Centroid compositions are normalized to Group 3; that is, the ratios $=$ Centroid $\mathrm{n} /$ Centroid 3 .

Table 6. Distance between group centroids (INCA Model 1).

\begin{tabular}{ccccccc}
\hline Group & 1 & 2 & 3 & 4 & 5 & 6 \\
\hline 1 & 0.000 & 4.405 & 3.334 & 29.537 & 41.076 & 18.316 \\
2 & - & 0.000 & 6.965 & 35.946 & 56.533 & 21.396 \\
3 & - & - & 0.000 & 36.537 & 52.275 & 24.025 \\
4 & - & - & - & 0.000 & 32.636 & 25.743 \\
5 & - & - & - & - & 0.000 & 23.307 \\
6 & - & - & - & - & - & 0.000 \\
\hline
\end{tabular}

These centroid compositions are displayed graphically in Figure 3 , in which they have been normalized to the most abundant group, (Group 3), which also is nearest the overall mean.

As may be seen from Figure 3 and Tables 5 and 6, Groups 1,2 , and 3 are closely related and exhibit a gradational change from one to another, while there is progressive separation from these toward Groups 4, 5, and 6. Differences between the groups occur mainly in the values of $\mathrm{TiO}_{2}$ and sulfur and, to a lesser extent, $\mathrm{FeO}^{*}$. $\mathrm{TiO}_{2}$ enrichment is more than eight times that of the average in Groups 4, 5, and 6, together with lesser, but significant, enrichments in $\mathrm{FeO}^{*}$. Sulfur is strongly enriched in Group 4, almost to a factor of 30 , and to a lesser extent in Group 5. $\mathrm{SiO}_{2}$ is also significant, but principally because as the amount of $\mathrm{TiO}_{2}$ and $\mathrm{FeO}^{*}$ increase, $\mathrm{SiO}_{2}$ decreases (closure). Some of these features may be seen in Figure 4, a crossplot of $\mathrm{SiO}_{2}$ vs. $\mathrm{FeO}^{*}$ for the whole data set. The separation of Groups 4, 5, and 6 is clearly seen. The parameter "Delta" in Table 5 confirms the importance of $\mathrm{TiO}_{2}, \mathrm{FeO}^{*}, \mathrm{SiO}_{2}$, and sulfur overall in group discrimination.

Groups 1,2 , and 3 are essentially olivine gabbro compositions, while Groups 4, 5, and 6 represent the Fe-Ti oxide-rich gabbros. Normative modeling of the centroid compositions suggests that Groups 1, 2, and 3 have, on average, $35 \%-50 \%$ plagioclase, $7 \%-10 \%$ olivine, and $2 \%-6 \%$ Fe-Ti oxides, together with pyroxenes and trace pyrite. Group 1 is the most mafic, through Group 3 to Group 2, which is richer in plagioclase. Group 3 has the lowest concentration of opaques, with $2 \%-2.5 \%$. Groups 4,5 , and 6 are all high in opaque minerals, with modeling suggesting $10 \% \mathrm{Fe}-\mathrm{Ti}$ oxide and $5 \%-6 \%$ pyrite on average in Group $4 ; 22 \%$ and $1 \%$, respectively, in Group 5; and $19 \%$ and less than $1 \%$ in Group 6. Groups 4 and particularly 5 have too much calcium for simple modeling, assuming a gabbroic mineralogy, and if the tool responses are basically correct, then alteration (calcite?) may be expected in association with these groups. Overall, the chemistry provided by the GLT can be modeled successfully, assuming gabbroic mineralogy, which suggests that there is relatively little alteration, compared, for example, with a similar study on Hole 504B (Harvey and Lovell, 1989).

Figures 5, 6, and 7 depict the logs for the GLT elements and INCA groups down the borehole. These data are grayshaded according to group membership, although a "group" $\log$ plotted with the arbitrary group number is given in Figure 5. From examination of the latter, six chemostratigraphic zones ( $\mathrm{Z} 1$ through $\mathrm{Z6}$ ) have been identified on the basis of the dominance of individual or group combinations. The abundance of groups within these zones is given in Table 7.

One may directly compare these derived zones with the lithostratigraphy established by the shipboard scientists. Zone $\mathrm{Zl}$ is comparable to Unit I and is characterized by a high abundance of Groups $1(61.82 \%)$ and $2(31.52 \%)$ responses, together with a small amount of Groups 4 and 5. This correlates well with the shipboard scientists' description of a metagabbro with a few Fe-Ti oxide-rich layers. Zone Z2 is thick (38-219.5 mbsf) and is dominated by Groups 1, 2, and 3, but features scattered layers of Groups 4,5 , and 6 , signifying a gabbro with scattered $\mathrm{Fe}$ - Ti oxide-rich layers. The most extensive $\mathrm{Fe}$-Ti oxide-rich layer extends from 103.6 to 111.2 mbsf. The first difference between INCA and SSP subdivision occurs within Zone Z2, where Unit III (180-224 mbsf) was not recognized. Unit III is described as being macroscopically similar to Unit II, but of a more evolved nature. Perhaps the poor accuracy in the values of magnesium derived by the GLT obscures this boundary.

Zone $\mathrm{Z3}$ is the most prominent (Figs. 5, 6, and 7) and is totally dominated by the Fe-Ti oxide-rich Groups 4, 5, and 6 . The SSP recognized this unit as a magnetite-ilmenite-bearing 
Plot of $x=$ Sio2 vs. $y=F e O \quad$ vs. $z=S$

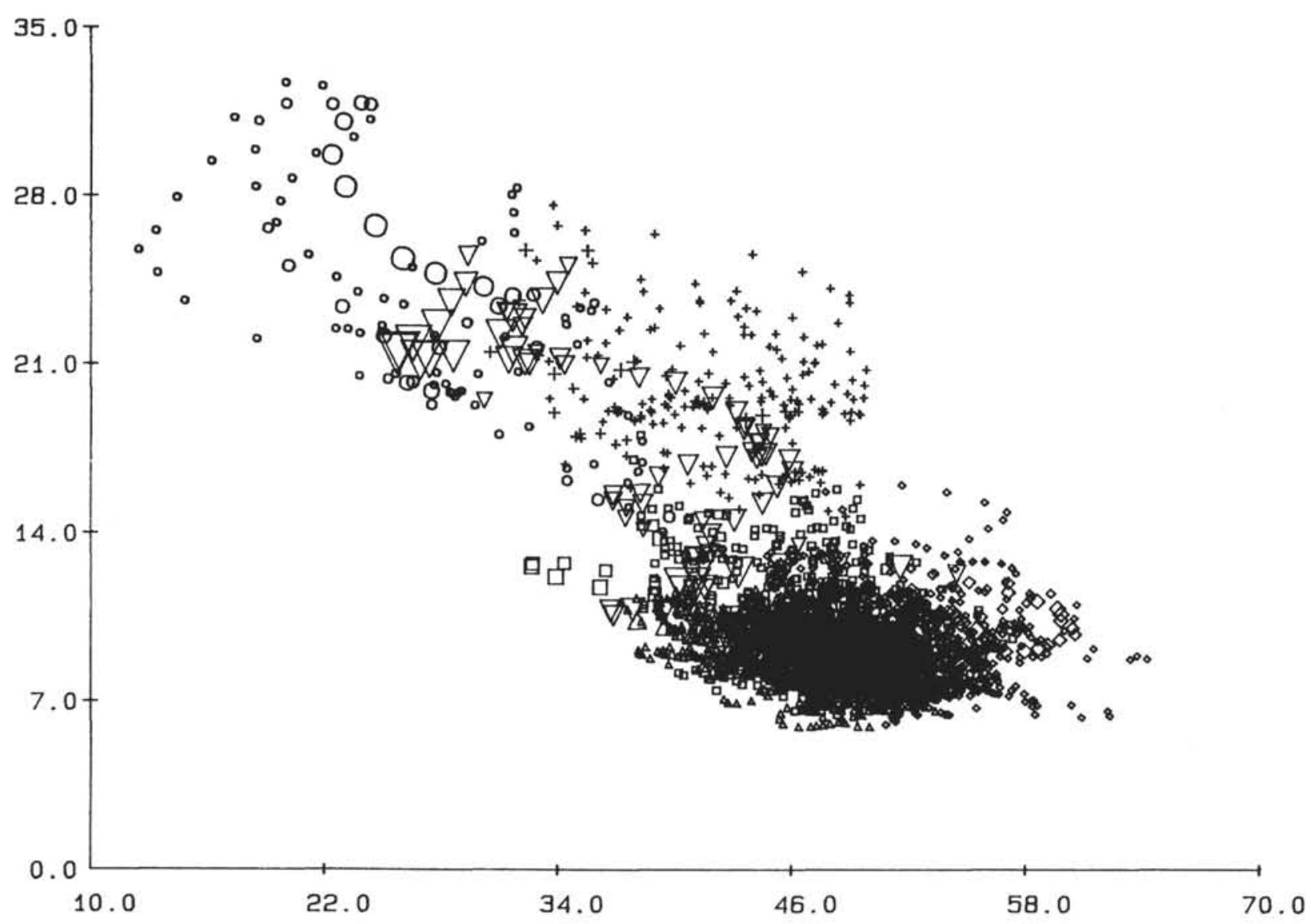

Figure 4. Crossplot of $\mathrm{SiO}_{2}$ (X-axis) vs. $\mathrm{FeO}^{*}$ (Y-axis). Symbol size is proportional to the concentration of sulfur. Squares represent Group 1; Group 2 is represented by diamonds; Group 3 is represented by triangles; Group $4=$ inverted triangles; Group $5=$ circles; and Group 6 = crosses. The high-density area on the plot is occupied mainly by the overlap of Groups 1,2 , and 3 .

gabbro; note that it was located (in terms of depth and size) precisely by the INCA of the GLT data. Zone Z4 is a small (8-m-thick) zone beneath Zone Z3 composed of $88.89 \%$ Group 2. This zone was not recognized as a separate unit by the SSP, being the top part of their Unit V. Zone Z5 is extensive (278.7-399.4 mbsf) and remarkably uniform (83.65\% Group 3 ), with a total absence of the high Fe-Ti oxide groups (4, 5, and 6). Again, this is in remarkable agreement with the equivalent Unit V (272.0-403.5 mbsf), which was described as a relatively uniform olivine gabbro characterized by a scarcity of Fe-Ti oxides. As noted, Group 3 has the lowest oxide concentration of all groups.

Zone Z6 is similar to Zone Z2 with a dominance of Groups 1,2 , and 3 , but also with scattered Fe-Ti oxide-rich layers. The mafic troctolite layers recorded in Units V and VI were not detected. Again, this may result from poor magnesium data, although some of the troctolites in Unit VI lie outside the logged interval.

\section{INCA Analysis of Derived Component Score Data (Model 2)}

This second analysis was performed using the component scores for the first four principal components, as discussed above. The fifth component, essentially sulfur, was not used. Statistically, this model is far superior to Model 1 because the principal component transformation effectively removes the intercorrelation from the variables, and one might expect that clustering with these data would produce additional information. Again, analysis of the "optimum" number of groups indicated that six should be extracted.

The group centroid compositions from this analysis are presented in Table 8 and Figure 8 , where they have been normalized to Group 1, numerically the most important group. In Figure 8, one can see that Groups 2 and 4 are near Group 1 , and both show slight depletions in all four components. Group 3 is also near Group 1, but shows significant depletion in the third principal component by a factor of -17.0 . Both Groups 5 and 6 are enriched in the third principal component, by a factor of 17.8 for Group 5 and a massive 79.0 for Group 6 ; the latter also exhibits an enrichment in the fourth principal component by a factor of 11.8 . Group 5 probably represents the felsic intrusive breccias that were recorded in Units IV and V. The centroid interdistance matrix is given in Table 9, from which one can see that Groups 5 and 6 are well separated from each other and from all other groups.

Figure 9 shows the component score logs, a group log, and the downhole distribution of the derived groups, again grayshaded according to group membership. The section has been subdivided into seven zones (P1 through P7) on the basis of the abundance of the various groups. Details are given in Table 10. Overall, the zones derived from the component scores are broadly similar to those obtained from the GLT data above.

Zone P1 extends from 13.0 to 82.9 mbsf and is dominated by Group 4, which accounts for $79.91 \%$ of the interval. This 

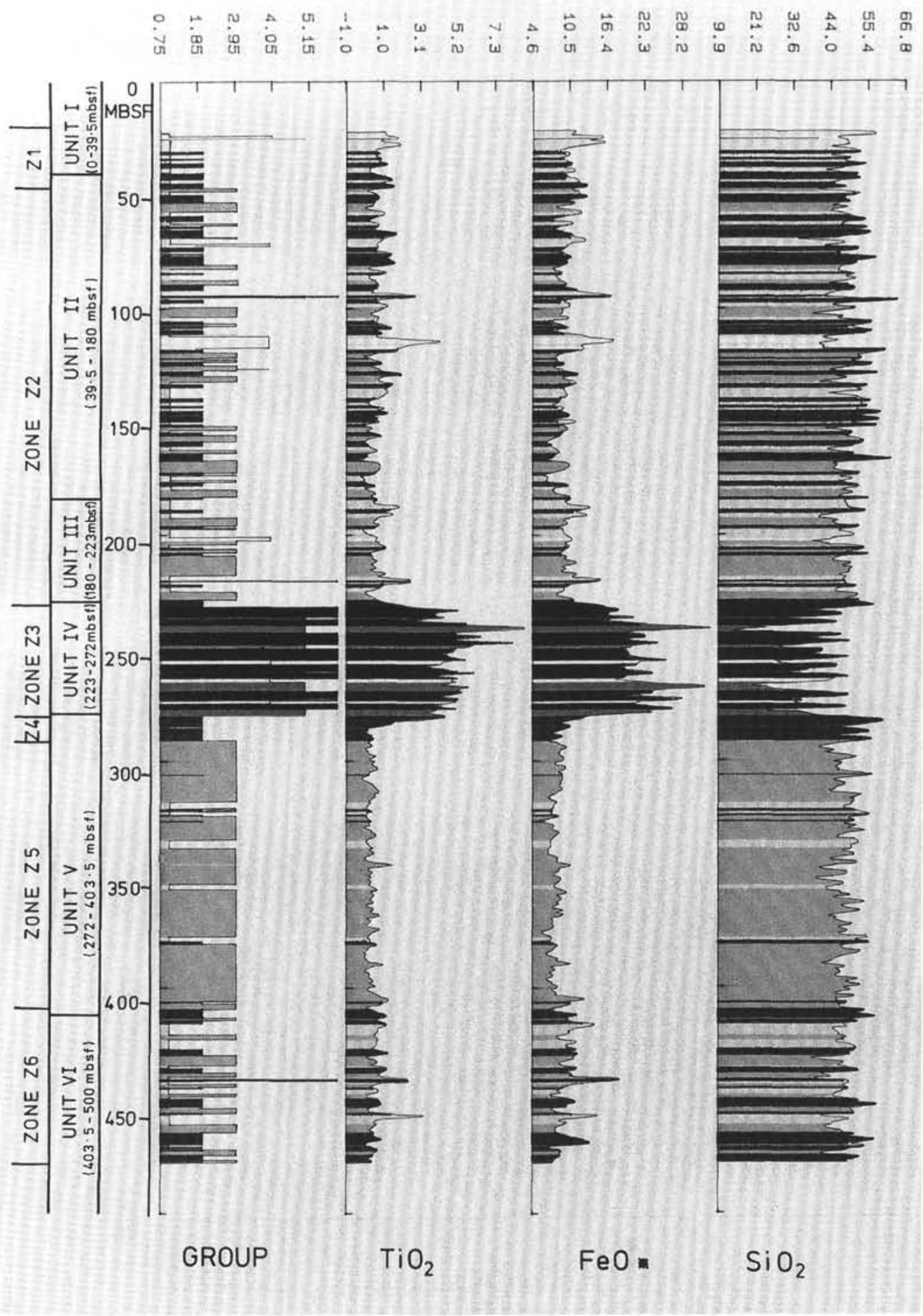

Figure 5. GLT log of Group, $\mathrm{TiO}_{2}, \mathrm{FeO}^{*}$, and $\mathrm{SiO}_{2}$. The log is shaded according to the INCA group. The first track (Group) shows group membership with depth. Group magnitudes are arbitrary.

zone encompasses part of Units I and II, but fails to pick out the boundary between these two units at 39.5 mbsf. Zone P2 (82.9-170.7 mbsf) constitutes $43.0 \%$ Group 1 and $38.7 \%$ Group 4 and is roughly equivalent to the remainder of Unit II. However, Unit II extends to $180 \mathrm{mbsf}$, which is within Zone P3. Zone P3 (170.7-220.5 mbsf) consists of $63.8 \%$ Group 1, $23.1 \%$ Group 4 , and $12.8 \%$ Group 3 . Zone P3 is equivalent to
Unit III (180-224 mbsf), which was unrecognized in the INCA analysis of the original GLT data.

There is good depth agreement between Zone P4 (220.5$270.9 \mathrm{mbsf})$ and Unit IV (224-272 mbsf). Zone P4 is $45.5 \%$ Group 2 and $39.76 \%$ Group 3; these groups clearly represent the $\mathrm{Fe}-\mathrm{Ti}$ oxide-rich gabbros. Zone P4 is the only zone in which Group 5 rocks occur, and these constitute $12.95 \%$ of the zone. 


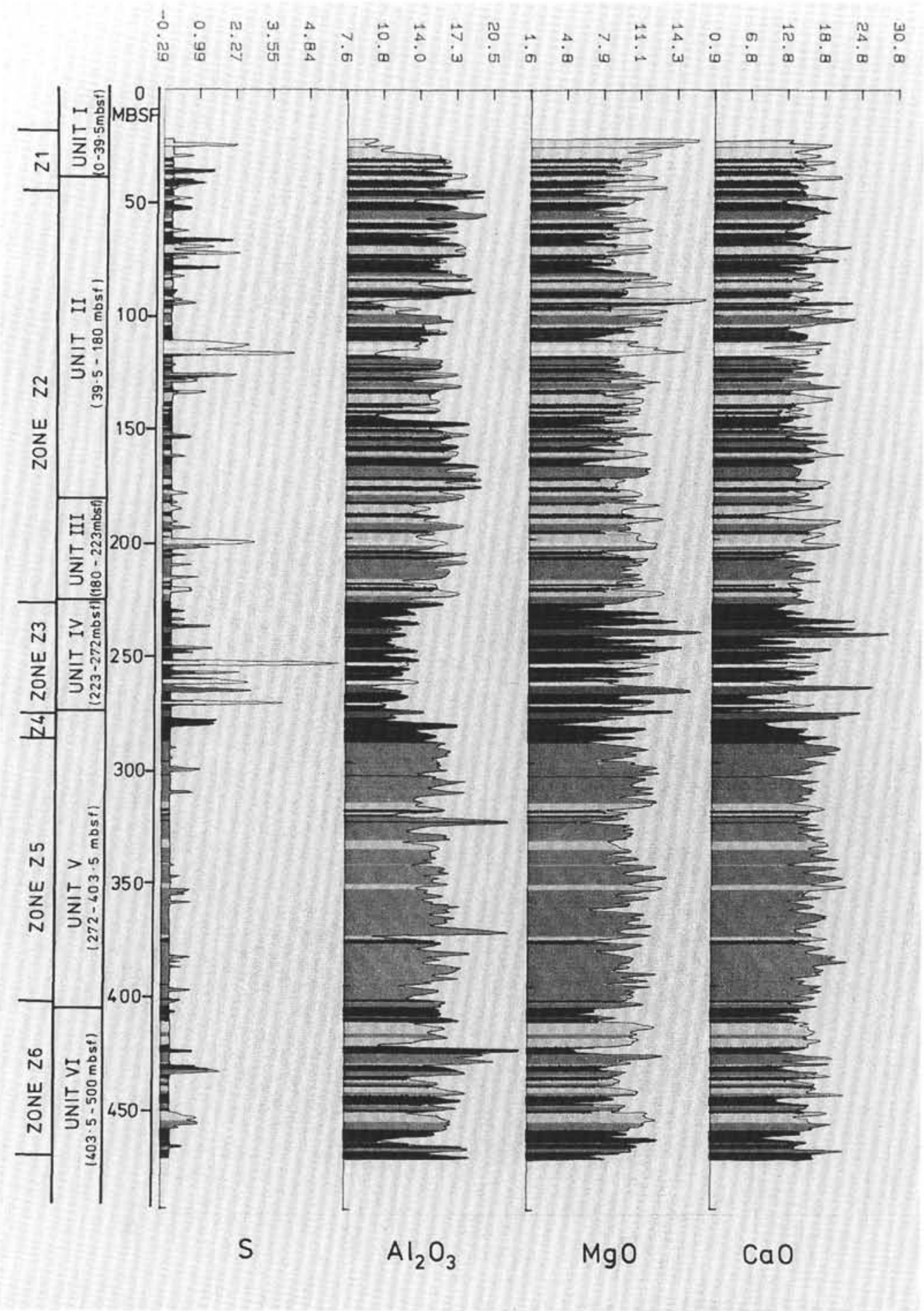

Figure 6. GLT log of $\mathrm{S}, \mathrm{Al}_{2} \mathrm{O}_{3}, \mathrm{MgO}^{\prime}$, and $\mathrm{CaO}$. Shading as in Figure 5.

Group 5 is dominated by the fourth principal component, and these rocks correlate with the felsic intrusion breccias observed in the core by the shipboard scientists. In Figure 9, the Group 5 rocks can be seen to be concentrated in two distinct layers. The upper, and larger, of these extends from 253.75 to 258.92 mbsf; it is underlain by a lower layer from 269.25 to $270.62 \mathrm{mbsf}$. More detailed investigation of the lower layer reveals that it is in fact made up of two smaller Group 5 layers separated by a thin (269.40-269.86 mbsf) layer of Group 2 rocks.
Zone P5 (270.9-281.2 mbsf) has no direct equivalent in the SSP classification, but can be clearly observed in the previous INCA, where it correlates with Zone Z4. Zone P6 (281.2$400.2 \mathrm{mbsf}$ ) is exceptionally pure, consisting of $89.2 \%$ Group 1 , being equivalent to the relatively uniform olivine gabbro of Unit V, which was also picked out by the first INCA. As with the first INCA, the base of Unit $\mathrm{V}$ was a prominent feature.

Zone P7 (400.2-468.0 mbsf) is compositionally similar to Zone P2, with $43.82 \%$ Group 1 and $43.37 \%$ Group 4 (this 

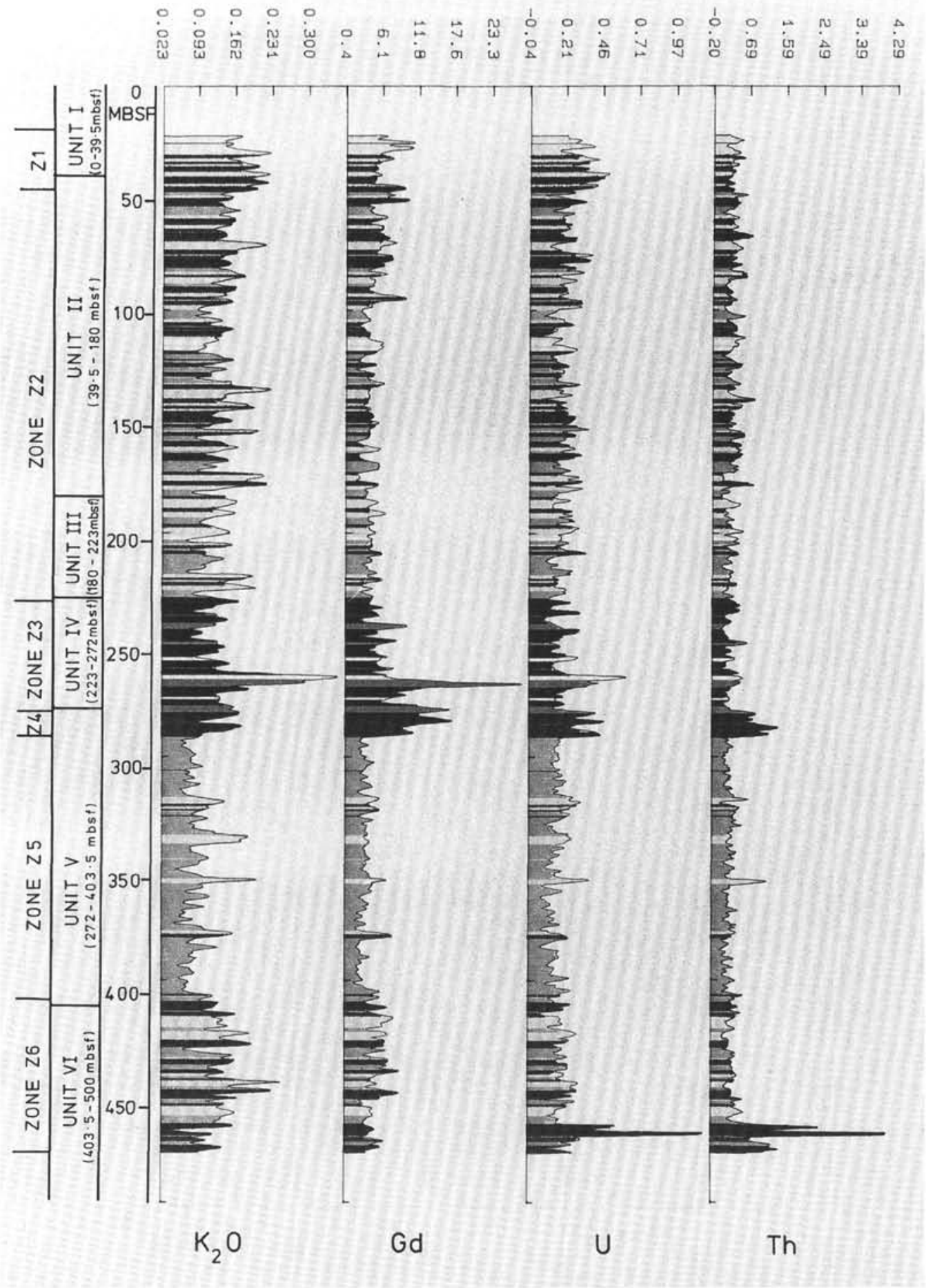

Figure 7. GLT $\log$ of $\mathrm{K}_{2} \mathrm{O}, \mathrm{Gd}, \mathrm{U}$, and Th. Shading as in Figure 5.

similarity was also noted between Zone Z2 and Z6). In Zone P7, only Group 6 rocks occur, where they constitute $4.9 \%$ of the zone. Group 6 is dominated by the third principal component, which is high in thorium and uranium. This layer may represent a permeable region and has been tentatively interpreted as either a thrust plane or a zone of hydrothermal mineralization.

\section{SUMMARY AND CONCLUSIONS}

Both statistically derived chemostratigraphic zonal sequences are in excellent agreement with the lithostratigraphy defined by the shipboard scientists. In particular, the $\mathrm{Fe}-\mathrm{Ti}$ oxide-rich gabbro interval (Unit IV) and relatively uniform olivine gabbro interval (Unit V) are picked out precisely by 
Table 7. Percentage compositions of zones (INCA Model 1).

\begin{tabular}{lcrrrrrr}
\hline Zone & $\begin{array}{l}\text { Depth } \\
\text { (mbsf) }\end{array}$ & $\begin{array}{c}\text { Gp1 } \\
(\%)\end{array}$ & $\begin{array}{c}\text { Gp2 } \\
(\%)\end{array}$ & $\begin{array}{c}\text { Gp3 } \\
(\%)\end{array}$ & $\begin{array}{r}\text { Gp4 } \\
(\%)\end{array}$ & $\begin{array}{r}\text { Gp5 } \\
(\%)\end{array}$ & $\begin{array}{r}\text { Gp6 } \\
(\%)\end{array}$ \\
\hline Z1 & $13.0-38.0$ & 61.82 & 31.52 & 2.42 & 3.03 & 0.61 & 0.00 \\
Z2 & $38.0-219.5$ & 38.91 & 27.70 & 28.87 & 3.60 & 0.42 & 0.42 \\
Z3 & $219.5-270.7$ & 0.89 & 5.00 & 0.00 & 11.53 & 27.22 & 54.73 \\
Z4 & $270.7-278.7$ & 9.26 & 88.89 & 0.00 & 0.00 & 0.00 & 0.00 \\
Z5 & $278.7-399.4$ & 11.95 & 4.28 & 83.65 & 0.00 & 0.00 & 0.00 \\
Z6 & $399.4-467.0$ & 36.18 & 34.38 & 28.09 & 0.00 & 0.00 & 1.12 \\
\hline
\end{tabular}

Table 8. Group abundance and centroid compositions (Model 2).

\begin{tabular}{lcrrrrr}
\hline \multicolumn{1}{c}{ Group } & 1 & 2 & 3 & \multicolumn{1}{c}{4} & 5 & \multicolumn{1}{c}{6} \\
\hline PC1 & 0.3919 & -2.3521 & -0.5997 & 0.2676 & -3.5607 & -0.1368 \\
PC2 & 0.5331 & 0.9831 & -1.1194 & -0.4527 & -1.2259 & -3.6329 \\
PC3 & 0.0742 & -0.2158 & -1.2633 & 0.1640 & 1.3175 & 5.8609 \\
PC4 & -0.3602 & -0.4213 & -0.7132 & 0.8269 & 2.1747 & -4.2359 \\
Number in & 1410 & 199 & 325 & 996 & 43 & 22 \\
$\quad$ group & & & & & & \\
\hline
\end{tabular}

both models. Distinctions among lithologic Units I, II, and III are not so definitive, but corresponding boundaries can be detected if the two chemostratigraphic sequences are combined. In some respects, this is slightly surprising because the essential distinction, at least between Units I and II, is textural (Unit I: foliated/mylonitic; Unit II: igneous textures). Of particular interest are the two zones within the $\mathrm{Fe}-\mathrm{Ti}$ oxide-rich gabbro unit, which have been picked out in Model 2 as possible felsic breccia zones.

Zones $\mathrm{Z} 3$ and $\mathrm{P} 4$ define a $10-\mathrm{m}$ region underlying Unit IV. This region, picked out clearly in both models, is seen (Figs. 5, 6 , and 7) to be characterized by relatively high concentrations of $\mathrm{SiO}_{2}, \mathrm{~K}_{2} \mathrm{O}$, uranium, and thorium. Like the occurrence toward the bottom of the logged section (Zone P7, Group 6), this was tentatively interpreted as a highly permeable and altered region, probably of tectonic origin. This interpretation has since been confirmed by reference to data from other logging tools and by detailed unit descriptions in the Initial Reports volume of Leg 118 (Robinson, Von Herzen, et al., 1989).

In part, this study set out to assess the use of GLT data when analyzing basement geology and also to establis'h tech- niques for characterizing and summarizing such information. The results presented show that the approach used can provide a meaningful chemostratigraphic subdivision of a borehole, without the aid of laboratory-analyzed core specimens and can also highlight geochemically anomalous zones. With continuing development of the GLT and the use of a boron sleeve, the quality of data, and hence information extracted, should increase significantly. Hole 735B was particularly valuable because large variations in bulk chemistry exist among rock units, and the derived zones have been interpreted in terms of the host rock composition. A more detailed study of these data may well allow scientists to recognize an alteration component.

\section{ACKNOWLEDGMENTS}

The authors thank colleagues for useful discussions. Particular thanks are due to Josie Wilkinson and David Jones at Nottingham University, whose drafting and photographic skills proved invaluable. This research forms part of a program of work funded by the Natural Environment Research Council under the Ocean Drilling Program Special Topic.

\section{REFERENCES}

Ball, G. H., and Hall, D. J., 1967. A clustering technique for summarizing multivariate data. Behavioral Sci., 12:153-155.

Brewer, T. S., Lovell, M. A., Harvey, P. K., Pelling, R., Atkin, B. P., and Adamson, A. C., 1990. Preliminary geochemical results from DSDP/ODP Hole 504B: a comparison of core and log data. Geol. Soc. (London) Spec. Publ., 48:195-202.

Harvey, P. K., and Lovell, M. A., 1989. Basaltic lithostratigraphy of DSDP/ODP Hole 504B. Nuclear Geophys., 3:87-96.

Hertzog R., Colson, L., Seeman, B., O’Brian, M., Scott, H., McKeon, D., Wraight, P., Grau, J., Ellis, D. V., Schweitzer, J., and Herron, M., 1989. Geochemical logging with spectrometry tools. Soc. Pet. Engrs. Formation Evaluation, 4(2):153-162.

Robinson, P. T., Von Herzen, R. P., et al. 1989. Proc. ODP, Init. Repts., 118: College Station, TX (Ocean Drilling Program).

Shepherd, A., Harvey, P. K., and Leake, R. C., 1987. The geochemistry of residual soils as an aid to geological mapping: a statistical approach. J. Geochem. Expl., 29:317-331.

Date of initial receipt: 6 July 1989

Date of acceptance: 4 May 1990

Ms 118B-160 


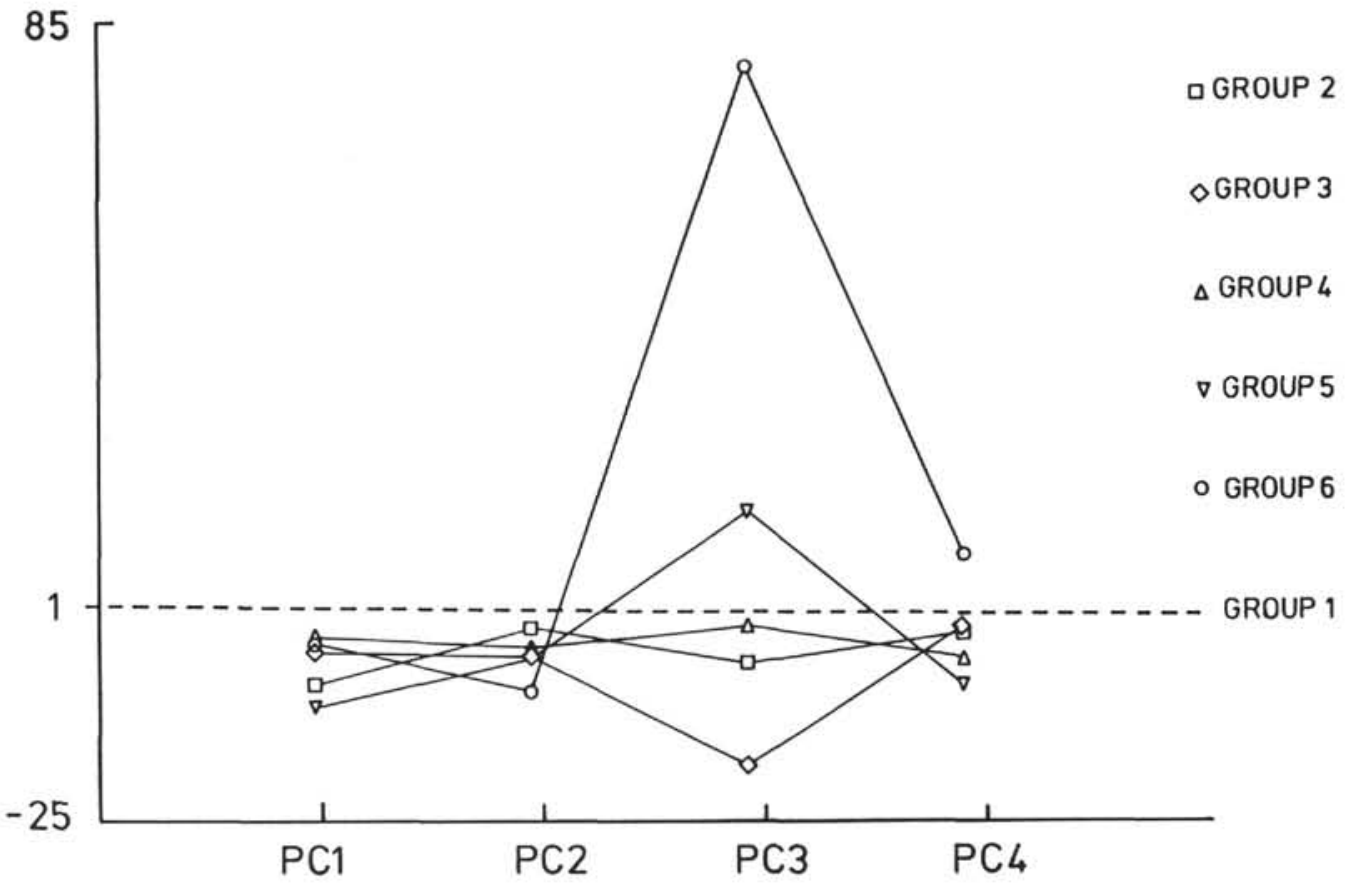

Figure 8. Spidergram of INCA (Model 2) centroids for the GLT component score data. Centroid compositions are normalized to Group 1; that is, the ratios $=$ Group centroid $n /$ Group centroid 1 .

Table 9. Matrix of distance between centroids (INCA Model 2).

\begin{tabular}{ccccccc}
\hline Group & 1 & 2 & 3 & \multicolumn{1}{c}{4} & \multicolumn{1}{c}{5} & \multicolumn{1}{c}{6} \\
\hline 1 & 0.000 & 7.820 & 5.628 & 2.405 & 26.688 & 66.283 \\
2 & - & 0.000 & 8.674 & 10.627 & 15.431 & 77.830 \\
3 & - & - & 0.000 & 5.606 & 23.779 & 69.822 \\
4 & - & - & - & 0.000 & 18.401 & 68.546 \\
5 & - & - & - & - & 0.000 & 79.486 \\
6 & - & - & - & - & - & 0.000 \\
\hline
\end{tabular}

Table 10. Percentage compositions of zones (INCA Model 2).

\begin{tabular}{lcrrrrrr}
\hline Zone & $\begin{array}{l}\text { Depth } \\
\text { (mbsf) }\end{array}$ & $\begin{array}{c}\text { Gp1 } \\
(\%)\end{array}$ & $\begin{array}{c}\text { Gp2 } \\
(\%)\end{array}$ & $\begin{array}{c}\text { Gp3 } \\
(\%)\end{array}$ & $\begin{array}{r}\text { Gp4 } \\
(\%)\end{array}$ & $\begin{array}{r}\text { Gp5 } \\
(\%)\end{array}$ & $\begin{array}{r}\text { Gp6 } \\
(\%)\end{array}$ \\
\hline P1 & $13.0-82.9$ & 11.45 & 1.51 & 6.91 & 79.91 & 0.00 & 0.00 \\
P2 & $82.9-170.7$ & 43.01 & 6.04 & 12.09 & 38.69 & 0.00 & 0.00 \\
P3 & $170.7-220.5$ & 63.83 & 0.00 & 12.77 & 23.10 & 0.00 & 0.00 \\
P4 & $220.5-270.9$ & 1.20 & 45.48 & 39.76 & 0.30 & 12.95 & 0.00 \\
P5 & $270.9-281.2$ & 0.00 & 0.00 & 21.74 & 76.81 & 0.00 & 0.00 \\
P6 & $281.2-400.2$ & 89.16 & 0.00 & 0.64 & 10.08 & 0.00 & 0.00 \\
P7 & $400.2-467.0$ & 43.82 & 1.35 & 6.52 & 43.37 & 0.00 & 4.94 \\
\hline
\end{tabular}




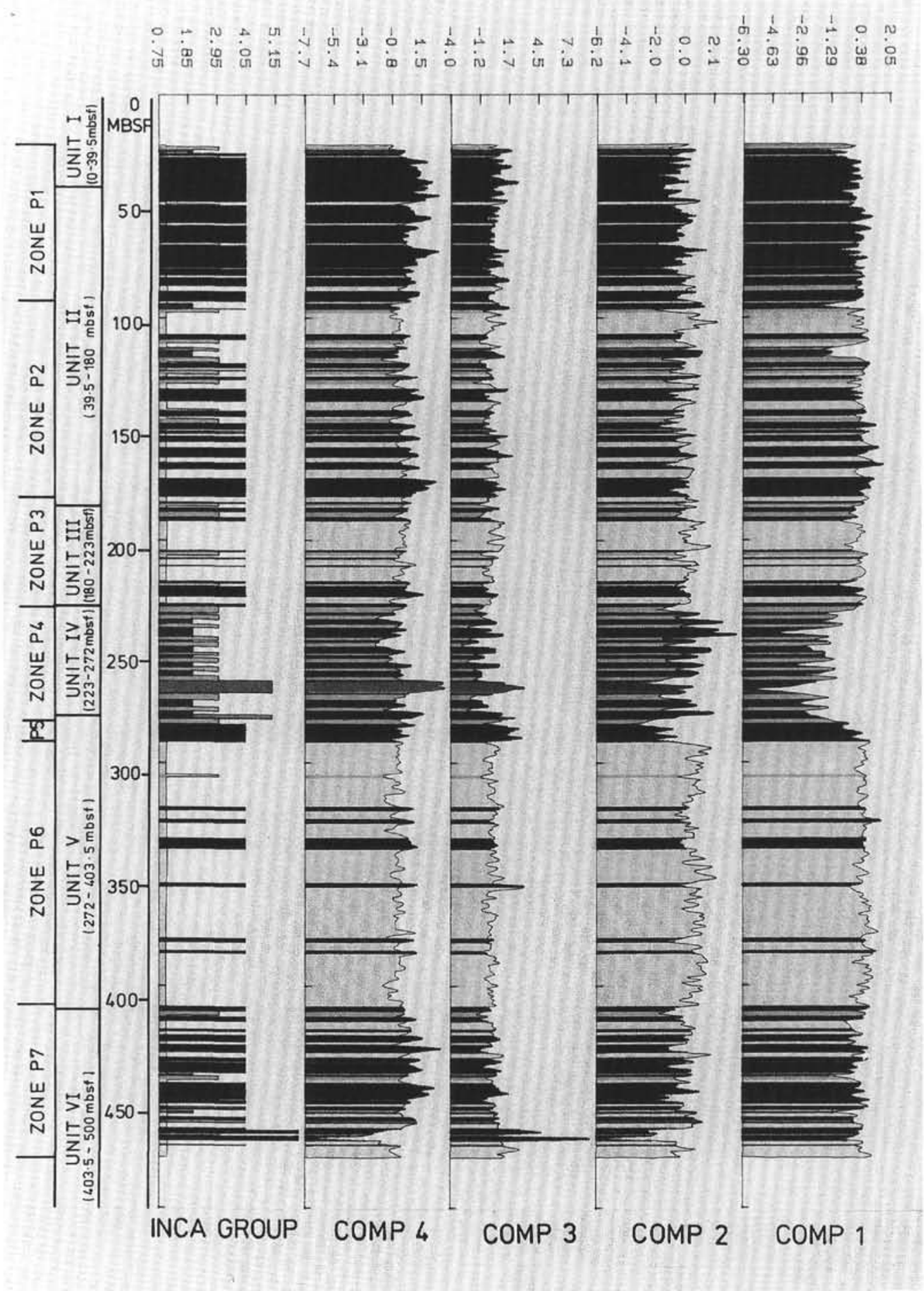

Figure 9. Component score log for the first four components and Group. The log is shaded according to the INCA group. The first track (Group) shows group membership with depth. Group magnitudes are arbitrary. 